\title{
Aniversário do Primeiro Plástico
}

\author{
Maria Elvira Callapez*
}

No passado mês de Junho comemorou-se o primeiro centenário daquele que viria a ser considerado um material ubíquo, indispensável, um verdadeiro símbolo de tecnologia do século XX. Referimo-nos ao plástico, um polímero que pode ser moldado em múltiplas formas. É inegável que nas sociedades industriais se encontram plásticos por todo o lado. E, mesmo em países subdesenvolvidos, a utilização dos plásticos é uma realidade e, por vezes, pelos piores motivos, como ilustra a inundação causada pelo entupimento dos sistemas de drenagem pelos plásticos (Figura 1). reira universitária, em Ghent, para se dedicar à indústria, nos Estados Unidos da América), anotou no seu caderno de laboratório a reacção química que viria a revolucionar o mundo industrial. $^{1}$

Acabava de sintetizar, por reacção entre o fenol e o formaldeído, a bakelite (baquelite), o primeiro plástico, material totalmente sintético, feito pelo homem. ${ }^{2}$ Criado o novo material, muitos outros se lhe seguiram e como em qualquer revolução, alguns encontraram obstáculos tendo vindo a desencadear sentimentos tão ambiva-

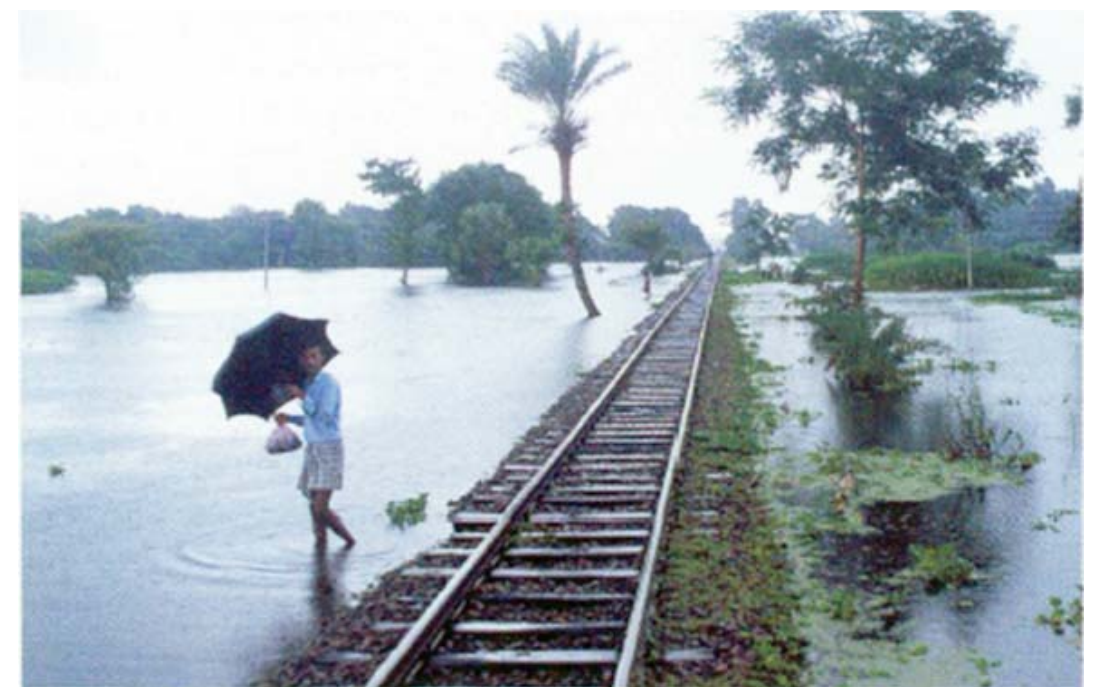

Figura 1 Homem recolhendo sacos de plástico [1] (Cortesia de Panos Pictures)

Por isso não é excessivo mencionar que as expressões "era dos plásticos", "idade dos plásticos", "revolução dos plásticos" são exaustivamente recorrentes. Basta olharmos para nós próprios, para o que vestimos, para o que comemos, para os objectos do nosso dia a dia, em casa ou no trabalho, para comprovarmos aquelas designações ...

Foi no dia 19 de Junho de 1907 que Leo Hendrik Baekeland (1863-1944), um químico norte-americano de origem belga (que renunciou a uma car- lentes e antagónicos, como simpatia e desprezo, amor e ódio!

Certamente a frase "Just one word: Plastics" pouco ou nada significará para a maioria dos jovens portugueses ou de outras nacionalidades, mas alguns dos seus pais e avós talvez conheçam o episódio sobre os plásticos, mostrado no filme "The Graduate", datado de 1968. Bem conhecido dos norte-americanos, este filme mostra na sua cena de abertura um Dustin Hoffman, recém graduado, tímido, inexperiente, a receber o conselho de

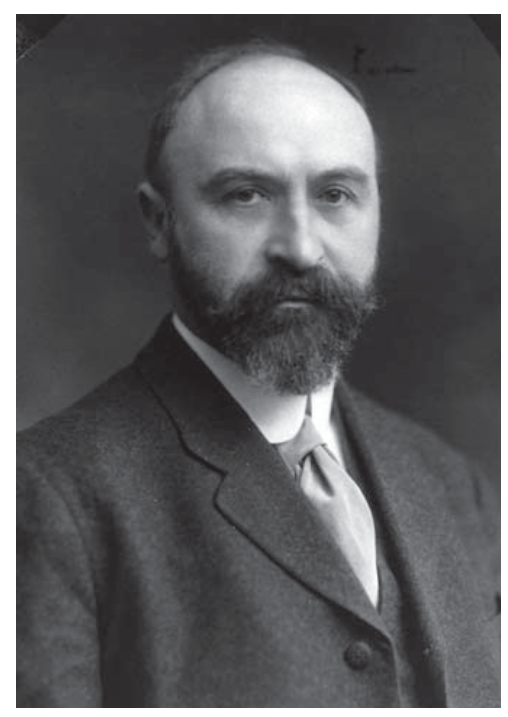

Figura 2 Leo Hendrik Baekeland [2] (Cortesia de Chemical Heritage Foundation Collections)

um amigo empresário sobre uma opção para a sua futura carreira profissional: "I just want to say one word to you. Just one word ... Plastics ... There's a great future in plastics".

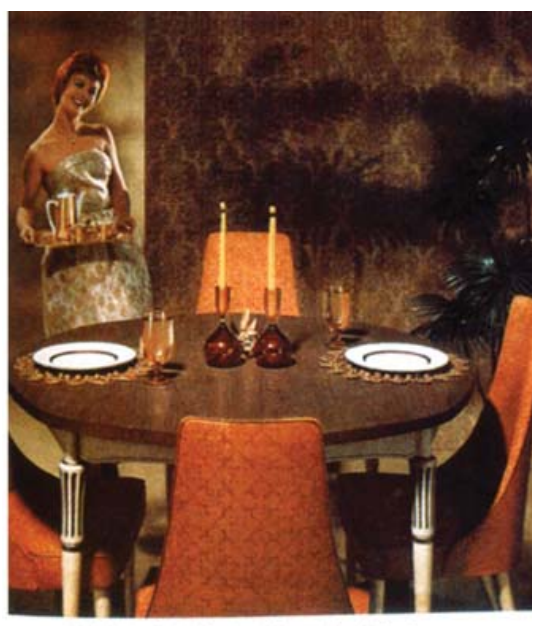

Cataline LAMINATING RESINS

Out to lunch: an all-plastic dining room, 1963.

Figura 3 Uma sala de jantar de plástico, 1963 [3] (Cortesia de Nature Publishing Group)

Embora, no contexto do filme, os plásticos simbolizem o materialismo banal da classe média e a sua su-

\footnotetext{
* Centro Interuniversitário de História das Ciências e da Tecnologia (CIUHCT), FCT, e University of California, Berkeley, Office for History of Science \& Technology

mariaelviracallapez@berkeley.edu
} 
perficialidade como produto, o que é certo é que os plásticos, actualmente, estão presentes em todos os lugares e, goste-se ou não deles, o seu volume de produção, em 1979, ultrapassou o do aço, o símbolo da revolução industrial $[4,5]$ ! É por isso que os plásticos, tal como aconteceu com a pedra, o bronze, o ferro e o aço, conseguiram atingir um reinado sob a designação de "Era do Plástico".

Os plásticos penetram diariamente nas nossas vidas, no nosso quotidiano sob as mais diversas formas e funções. Mesmo aqueles que possuem uma imagem negativa dos plásticos, utilizando o adjectivo plástico como sinónimo de falso, superficial, trivial, artificial e aliando, no plano cultural, a palavra "plásticos" a "plasticidade" de uma sociedade, caracterizada por certo artificialismo, por padrões comportamentais postiços, destituídos de conteúdo e valores, usam diariamente e inúmeras vezes os objectos de plástico. Estando o mundo contemporâneo de tal ordem rodeado de plásticos, porque é que o grande público, desde as classes mais favorecidas até às menos favorecidas economicamente, passando por velhos, jovens, rurais e urbanos, não olha para eles como uma classe especial de materiais [5]? O que sabe o cidadão comum sobre os plásticos e as suas vantagens? Talvez para a maioria o plástico esteja associado apenas a objectos baratos, que se compram em qualquer loja e em qualquer lugar. No entanto, estes objectos devem muito à investigação científica e tecnológica. Os plásticos são materiais/polímeros sintéticos e, como tal, não são construídos pela natureza mas sim construídos pelo homem, fruto do enorme esforço, imaginação e investigação de várias gerações de cientistas [6,7]. Para produzir os materiais sintéticos, o homem pode fazer uma lista de propriedades que gostaria de incorporar num material e, dentro de certos limites, pode personalizar esse material [6]. Porém, tal tarefa exige o maior investimento, seja do químico mais criativo, do físico, do engenheiro, do designer, do historiador, num campo cada vez mais aberto à exploração de novos materiais e aperfeiçoamento dos existentes.

Porquê e como surgiram os plásticos? Quais as motivações que estiveram na origem da sua produção? Uma das razões passou pela necessidade de encontrar materiais mais baratos e mais disponíveis do que os tradicionais. O exemplo mais famoso é o do norte-americano John Wesley Hyatt que "descobriu", em 1870, o celulóide, um semi-sintético, resultante de uma modificação química da celulose. ${ }^{3}$ Este semi-sintético "substituiu" o marfim utilizado no fabrico das bolas de bilhar e rapidamente os seus artigos começaram a ser apreciados e utilizados pelas classes mais abastadas durante a faustosa época vitoriana. O celulóide, apesar de ter encontrado inúmeras aplicações, era inflamável. Na memória de muitos de nós, permanecerá a triste imagem, passada no "Cinema Paraíso", filme produzido em 1988 por Giuseppe Tornatore, das labaredas de um violento fogo devidas ao incêndio do filme de celulóide.

Depois do celulóide, a grande descoberta foi a baquelite, levada à grande produção em 1910. Tal como Hyatt, Baekeland andava à procura de um substituto para o "shellac", um material caro e muito requisitado devido às suas propriedades isoladoras. Durante as suas pesquisas e trabalhos laboratoriais obteve a baquelite, por reacção de condensação entre o fenol e o formaldeído (Figuras 4 e 5).

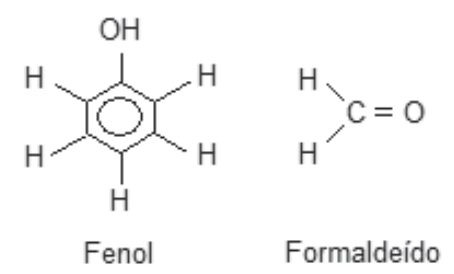

Figura 4 Estruturas químicas do fenol e do formaldeído
Já antes de Baekeland outros químicos tinham tentado esta reacção mas obtinham substâncias duras, difíceis de moldar e por isso com pouca utilidade. ${ }^{4}$ Porém, ao contrário dos seus antecessores, Baekeland percebeu que só impondo condições de temperatura e pressão específicas conseguia controlar a dureza das suas resinas e portanto moldá-las. E foi em resultado desse longo trabalho de investigação sistemática que obteve uma resina moldável, insolúvel e infusível - a baquelite - com boas propriedades eléctricas e mecânicas, com potencialidades comerciais, que de imediato encontrou inúmeras aplicações, nomeadamente, nas indústrias eléctrica, de telecomunicações, automóvel e da rádio.

A partir do aparecimento da baquelite, tanto o período inter-guerras como o pós-guerra assiste à massificação do consumo de plásticos (termoplásticos) como os aminoplásticos, o poliestireno, o policloreto de vinilo, o polietileno, os acrílicos, o "teflon", etc. ${ }^{5}$ Os termoplásticos, materiais bastante significativos no período pós II Guerra Mundial, foram substituindo os termoendurecíveis, dominantes durante o período Inter-Guerras. De materiais "estáveis, inertes e quase imortais", cuja formação sob a pressão e temperatura se caracterizava por um processo irreversível, passou-se para materiais "instáveis, facilmente fundidos e moldáveis" [8]. Para Jeffrey Meikle, professor de estudos americanos e história de arte, os termoplásticos reflectem "an expansive culture of impermanence" [8]. Esta mudança de algo permanente para algo instável, leva Meike metaforicamente a considerar que “ (...) plastic became a means of creating an abundance ephemeral waste. A thermoset world melted into thermoplasticity" [8].
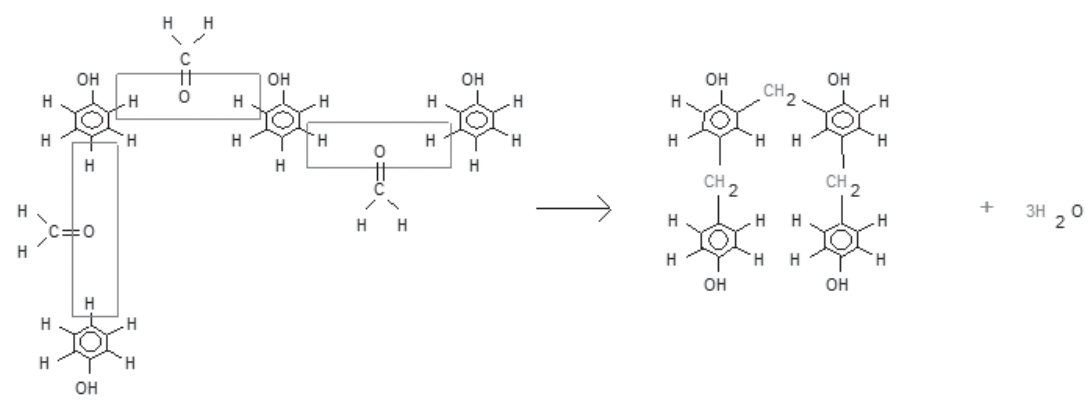

Figura 5 Esquema de condensação da baquelite 
Estes materiais adquirem, assim, maturidade e independência e deixam de ser vistos como "ersatz", materiais triviais, de segunda categoria, inferiores, de substituição, de imitação e até se lhes atribui o estatuto de nobreza. Numa imagem metafórica interessante, é inclusivamente o primeiro plástico, a baquelite, a ser elevado a essa condição: "the aristocrats of plastics - if the industry can be considered old enough to have an aristocracy - are the phenolics, of which Bakelite is the sire" [9]. De facto, sempre que provam ser os melhores para fins específicos, os plásticos têm ganho a competição com os materiais tradicionais (vidro, ferro, madeira, ligas metálicas, pedra, porcelana, etc.).

Após a Segunda Guerra Mundial a indústria de plásticos, nomeadamente a americana, importunada com a imagem negativa sobre os seus materiais, devido a algumas más aplicações dos plásticos, lançou uma campanha a seu favor traduzida em editoriais como "Let's use the word "Plastics" with pride! Let's kill all thought of plastics as substitutes. Let's emphasize their tremendous importance in peace and war. Use the Word "Plastics" with Pride!" ... "Image please" ... "What does the public know of plastics?" [10] Paradoxalmente ou não, os plásticos dificilmente poderão ser destronados porque cada vez mais a inovação científica e tecnológica permite, a um ritmo extraordinário, o desenvolvimento de novos plásticos, novos processos, novas aplicações e com as características que se pretende.

Por outro lado, em resultado das suas particularidades, os plásticos, materiais de inovação, dão azo à mais proveitosa imaginação. Por exemplo, se existisse um mundo sintético, colorido, constituído por continentes de plástico (Synthetica - Figura 6), habitados pelo "homem de plástico" tal como utopicamente idealizado, respectivamente, na Fortune e na Science Digest, no início de 1940, haveria um mundo perfeito, independente de recursos naturais localizados, em que o homem faria tudo à sua medida para satisfação das suas necessidades $[11,12]$. Conceberia um mundo mais brilhante, mais igual na distribuição dos meios materiais, mais limpo, e não existiriam críticas e acusações aos plásticos de agentes poluidores de rios, mares, solos, entre outros.

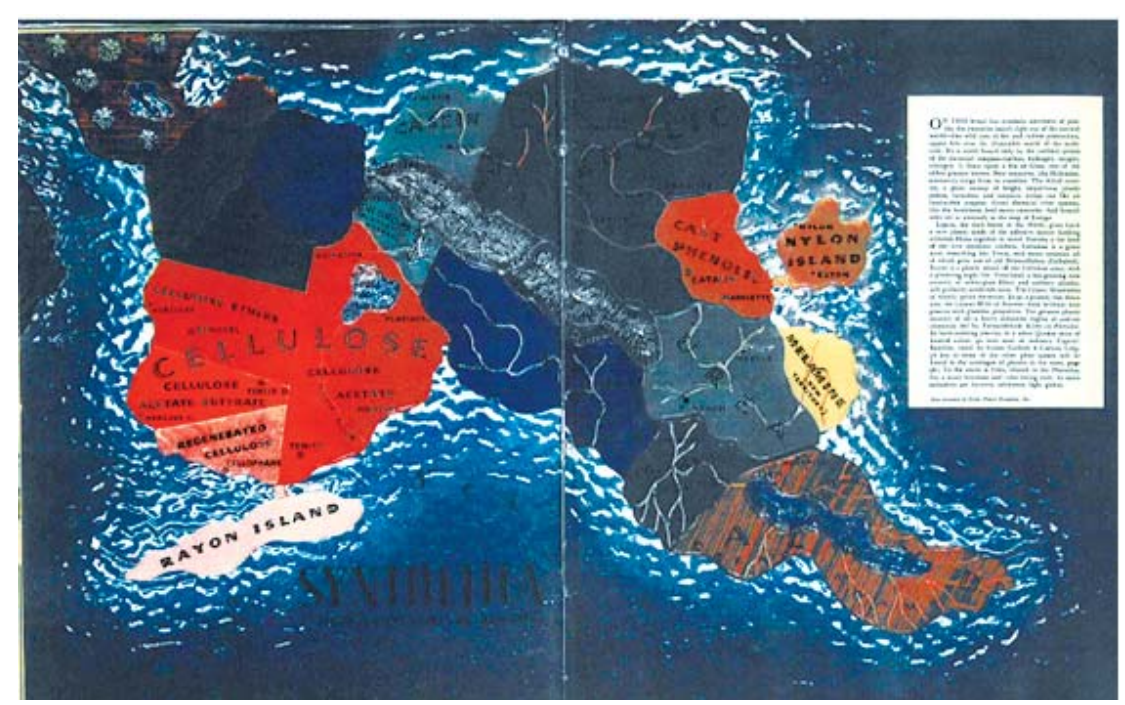

Figura 6 "Synthetica: A New Continent of Plastics", Fortune, Outubro de 1940
Diferente do cenário do mapa "Synthetica" onde se destaca uma geografia, bem delineada, dos países sintéticos, outro exemplo do reino da ficção, conduz-nos ao "An American Dream of Venus" (Figura 7). Aqui surge uma panóplia de objectos de plástico que, nas palavras de Meikle, parecem desafiar qualquer razão [13]. Eles parecem surgir do nada, escapando do domínio dos materiais naturais e espalham-se sobre o torso de uma deusa de acrílico, a Vénus de plástico, e pelo ar, à sua volta, criando uma imagem que "promised an American dream of shifting shapes, an irrational phantasmagoria of ungrounded, disconnected images, all in brilliant synthetic colours, a carnival of material desire" [13]. sente no nosso quotidiano, porventura só atrai a nossa atenção no âmbito da discussão sobre poluição ambiental,

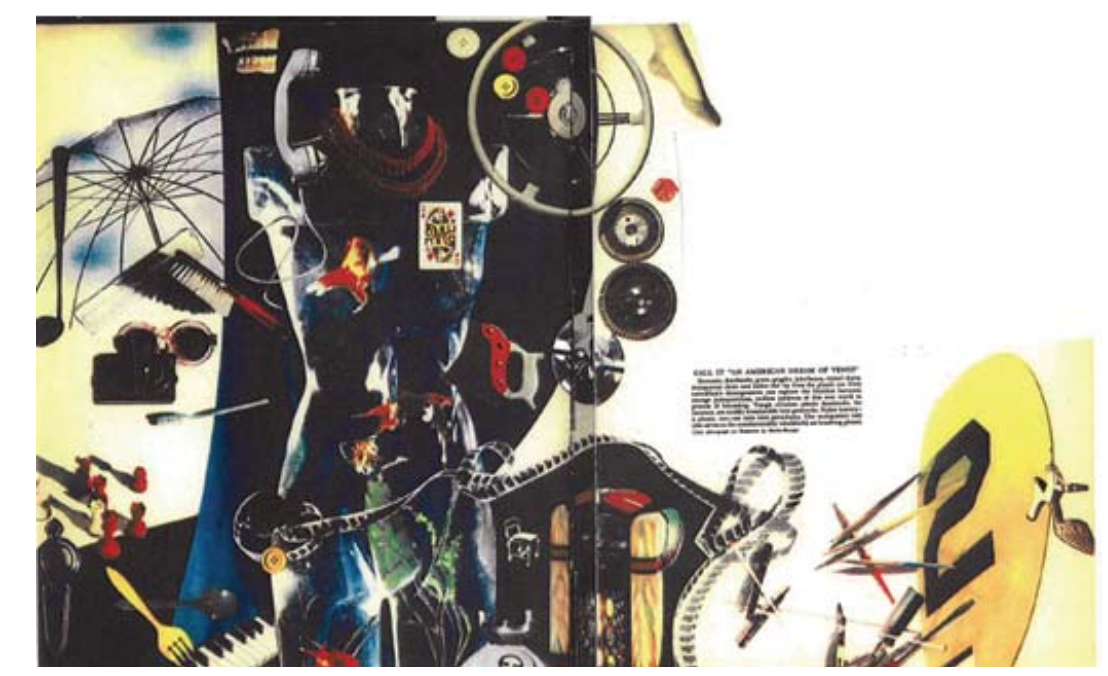

Figura 7 "An American Dream of Venus", Fortune, Outubro de 1940
O plástico, por ser visto como um material milagroso e por estar tão pre- resíduos tóxicos, co-incineração e ser ou não biodegradável. Apesar desta estranha relação entre os plásticos e o público, faz todo o sentido transpor para a actualidade a questão levantada nos idos 1970s " (...) if they hate plastics so much, how come they're buying more and more of it?" [14] Ora, consomem-se cada vez mais plásticos pelos benefícios que estes materiais sintéticos oferecem não só em termos de custos de fabrico, como também devido à facilidade com que esta área se desenvolve ao aperfeiçoar as técnicas de fabrico e ao produzir novos e melhores materiais. Apesar de, por vezes, se comparar estes materiais ao "camaleão", por "imitarem" o vidro, o ferro a madeira, a porcelana, a lã, o mármore, a pedra, o metal, podemos assegurar que, em consequência das inovações científica e tecnológica, os plásticos têm adquirido notoriedade 
e importância social e económica, graças à sua versatilidade e possibilidades técnicas superiores. Corroborando as previsões lançadas em 1940 por Yarsley e Couzens, hoje em dia é mais comum perguntar-se que tipo de plástico se vai utilizar para produzir um artigo, do que o tipo de material que se vai usar ... [12]. Sem exagero, os plásticos continuarão a surpreender-nos por muito tempo pois este é, sem dúvida, um campo em constante evolução e progresso.

\section{Notas}

1 Já em 1899, Baekeland inventara o Velox, um papel para fotografia, façanha que o fez ganhar uma fortuna.

${ }^{2}$ A baquelite é um termoendurecível ou termoestável. São termoendurecíveis, os polímeros que endurecem durante o seu processo de fabrico e moldagem a quente. Solidificam formando um corpo sólido e estável, o que impede a sua posterior re-utilização. Portanto, não podem ser novamente transformados, i. e., amolecidos e moldados. Na sua forma de emprego são duros e rígidos e decompõem-se ao serem aquecidos acima de uma determinada temperatura. Exemplos: resina, ureiaformaldeído, as resinas epóxi, a borracha vulcanizada e alguns poliuretanos. Sobre este assunto cf. Tese de mestrado defendida em 1998, na FCT-UN: Maria Elvira Callapez, A Origem da Indústria Transformadora de Plásticos em Portugal, Monte de Caparica/Lisbon, Faculdade de Ciências e Tecnologia - Universidade Nova de Lisboa, 1998; Maria Elvira Callapez, Os Plásticos em Portugal - A Origem da Indústria Transformadora, Editorial Estampa, Lisboa, 2000.
3 Já em 1862, o inglês Alexander Parkes tinha sintetizado a Parkesine, também um semi-sintético, derivado da celulose, mas com propriedades inferiores às do celulóide. Cf. Maria Elvira Callapez, op. cit., A Origem da Indústria Transformadora de Plásticos em Portugal.

4 Antes da descoberta de Baekeland, químicos como Sir James Swinburne, Adolf von Baeyer, Werner Kleeberg e Adolf Luft, entre outros, produziram massas duras e viscosas através da reacção do fenol com o formaldeído, mas nunca se aperceberam das potencialidades desses produtos (S. T. I. Mossman e P. J. T. Morris, The Development of Plastics, The Royal Society of Chemistry, Cambridge, 1994).

5 Estes materiais pertencem à categoria dos termoplásticos - polímeros duros à temperatura ambiente, mas moles e flexíveis a temperaturas elevadas. Assim, podem ser moldados plasticamente tantas vezes quantas necessárias, voltando ao estado sólido depois de arrefecidos. Exemplos: polietileno, o poliestireno, o polipropeno, o policloreto de vinilo (PVC), os acrílicos e o «nylon».

\section{REFERÊNCIAS}

[1] Angela Spivey, "Recycling: Plastic Bags. Prolific Problems", Environmental Health Perspectives 111 (2003) A208. Ver também Maria Elvira Callapez, "Paper or plastic"?, Ciência Hoje - Ciência e Tecnologia em Directo, 7 Março 2006 (http://www.cienciahoje. pt/index. php?oid=2619\&op=all); Elvira Callapez, "Alguém consegue viver sem plásticos?”, De Rerum Natura, 4 Junho 2007 (http://dererummundi.blogspot. com/2007/06/algum-consegue-viversem-plsticos.html).
[2] Newsmagazine of the Chemical Heritage Foundation 25 Summer (2007) 16.

[3] Howard P. Segal, "From durable to disposable", Nature 379 (1996) 781-782.

[4] Eileen Boris, The American Historical Review 102 (1997) 561-562.

[5] Jeffrey L. Meikle, "Plastic, Material of a Thousand Uses" in Joseph J. Corn, Imagining Tomorrow - History, Technology, and the American Future, The MIT Press, Cambridge, Massachusetts, 1986.

[6] Joseph L. Nicholson, George R. Leighton, "Plastics come of age", Harper's Magazine, August (1942) 300- 307.

[7] L. H. Woodman, "Miracles? ... Maybe", The Scientific Monthly 58 (1944) 421- 426.

[8] Jeffrey L. Meikle, American Plastic: A Cultural History, N. J. Rutgers University Press, New Brunswick, 1995.

[9] "What Man Has Joined Together", Fortune March (1936) 68-75 e 143--150.

[10] a) Editorial, "Let's use the word "plastics" with pride", Modern Plastics 28 (1951) 5 ; b) Editorial, "Image please", Modern Plastics 46 (1969) 43; c) "What does the public know of plastics?", Modern Plastics 24 (1946) 5 e 222.

[11] "Plastics in 1940", Fortune 22 (1940) 89-96 e 106 e 108.

[12] V. E. Yarsley e E. G. Couzens, "The Expanding Age of plastics", Science Digest December (1941) 57- 60.

[13] Jeffrey L. Meikle, "Into the Fourth Kingdom: Representations of Plastic Materials, 1920-1950", Journal of Design History 5 (1992) 173-182

[14] "What is plastics image, anyway", Modern Plastics 47 (1970) 66-70.

\section{Actualidades Científicas}

A Samsung há muito que anuncia o seu interesse em equipar os dispositivos móveis que vende com células de combustíveis, nomeadamente computadores portáteis, PDA's e telemóveis. A semana passada o gigante sul-coreano anunciou que lançará, muito provavelmente ainda em 2007, um portátil, o Sense Q35, alimentado por uma célula de combustível com uma autonomia assombrosa: podemos utilizá-lo oito horas por dia, cinco dias por semana durante um mês sem recarga.

Uma empresa norte-americana, a Medis, antecipou-se, no entanto, à Samsung e a sua página anuncia já a primeira célula de combustível comer- cial, o Medis 24/7 Power Pack que servirá para carregar baterias convencionais de telemóveis, ipods e dispositivos similares. Os progressos do "primo» mais potente do $24 / 7$, que se destina a recarregar portáteis, serão apresentados no Intel Developer Forum, em São Francisco.

Embora quando se fala em células de combustível se pense imediatamente em pilhas de hidrogénio, na realidade pode-se usar qualquer combustível e a Samsung escolheu o metanol na sua Direct Methanol Fuel Cell. A Medis optou por hidrogénio produzido in situ a partir de um sal de borohidreto. A vantagem das pilhas de combustível em relação às restantes são óbvias: apre- sentam autonomia e vida útil (desde que seja fornecido o combustível e oxigénio ou ar) muito superior a todas as tecnologias de baterias actualmente disponíveis.

O Brasil foi nos dias 24, 25 e 26 de Setembro o anfitrião de um evento, o Brasil H2 Fuel Cell Expo/Seminar 2007, em que universitários e investigadores de empresas como a General Motors ou a BASF Fuel Cells, discutiram temas relacionados com a produção, armazenamento, distribuição, tecnologia e aplicações das pilhas de hidrogénio! Como os anúncios da Samsung e da Medis indicam, a energia do futuro está a chegar! 